\title{
Do child care subsidies increase the labour force participation of women in Australia?
}

\author{
Luke Andrews, Bhim Prasad Neopanay, Kumara Yaddehige, Jaye Jorgensen
}

\begin{abstract}
We hypothesise that child care subsidies increase the labour force participation of women within Australia. Our alternative hypothesis is that child care subsidies do not increase the labour force participation of women in Australia. This research pulls data from the Australian Bureau of Statistics, the Organisation for Economic Co-operations, Development and the Productivity Commission and Department of Education, Employment and Workplace Relations (DEEWR). Based on the regression analysis performed, we found that there was a notable positive relationship between the labour force participation rates of Australian females and child care subsidies by the Australian government. Nevertheless, it's relevant to highlight that our data could be impacted by other considerations such as taxation changes coming out of the government and the apparent positive relationship between female employment and education over time.
\end{abstract}




\section{Introduction}

It is generally perceived that, if child care was more affordable, more mothers would opt to work. The enactment of Child Care Act 1972 by the Australian government gave impetus to child care subsidies in Australia (Department of Education, Employment and Workplace Relations (DEEWR) 2010, Irvine \& Farrell 2013). Child care is categorised as either formal, which is regulated and subsidised, and informal, which is neither regulated nor subsidised.

While there are obvious benefits to the child care subsidy, its relationship to women's labour force participation (WLFP) has been contentious ever since its inception. Nevertheless, consistent with the findings of Robins (1988), Brayfield (1992) (cited in Kimmel 1998) and Schofield and Poltte (1998) (cited in Rammohan \&Whelan 2007), the Australian government has embraced the argument that increase in child care use enhances WLFP (DEEWR 2012). It follows that subsidising child care cost enhances WLFP. This is important because it provides the basis for policy-planners and decision makers. Therefore, the hypothesis of this study is that child care subsidies increase the labour force participation of women in Australia while the alternate hypothesis is that child care subsidies do not increase the labour force participation of women in Australia.

Our intention is to run regressions between two variables -- government expenditure on child care subsidy (GECCS) (independent variable) and WLFP (dependent variable) -- to test the degree of association between them and to gauge the impact of GECCS on WLFP. To do so, we will focus on two time periods namely 1978-1991 and 1992-2005. The rationale for this sample approach is that child care underwent major restructuring in Australia leading to significant increase in GECCS starting from 1992 (Childcare in Australia 2013). Although, we had data on GECCS starting from 1975, it was not used in our analysis since the data on WLFP were missing for the period 1975-1977. Further, our study could not be extended beyond 2005 due to lack of publicly available data. 


\section{Literature review}

Numerous studies exist in this area. Connelly (1992) demonstrates that married women's labour force participation rate is not only sensitive to average child care cost but also has a negative relationship with the predicted cost of child care. Further, Connelly identifies higher cost of child care as the sole reason for lower rate of labour force participation among mothers with preschool children. It follows that reducing the cost of child care by way of subsidy will bring about a positive change in WLFP.

Like other developed countries, Australian women with small children considerably limit their labour force participation (Australian Bureau of Statistics (ABS) 2007, p. 3). Child care subsidies is one important element influencing parents' decision, when encountered with two choices: employment versus child care (ABS 2007, p. 4-5). Hence, it is rational to say that affordable child care cost will encourage more mothers to work. This being consistent with the findings of Brayfield (1992) and Robins (1988) (cited in Kimmel, 1998) where they conclude that child care costs can be a hurdle to employment for mothers.

In a more recent Australian study involving households with couples, Breunig, Gong \& Trott argue that increase in child care cost will have an inverse effect on married women's employment causing women's average hours of work to decrease (2012, p14). According to Hegewisch \& Gornick (2011), this inverse effect is more substantial for less educated mothers as compared to mothers with higher levels of education.

On the other hand, there are persuasive arguments to back the alternative hypothesis. Francis Teal (1992) conducted an independent study that found there was no feasible evidence to suggest that child care subsidies would be an effective means of increasing female employment. This was given more weight by a study published by Rammohan and Whelan (2005, p.216) that says, given the decision to work, married mothers don't put much weight into the cost of child care; meaning subsidies may not be an overly influential factor to the decision to return to the labour force for some women. 
Figure 1: Correlation on Government Expenditure on Childcare vs. Employed Females

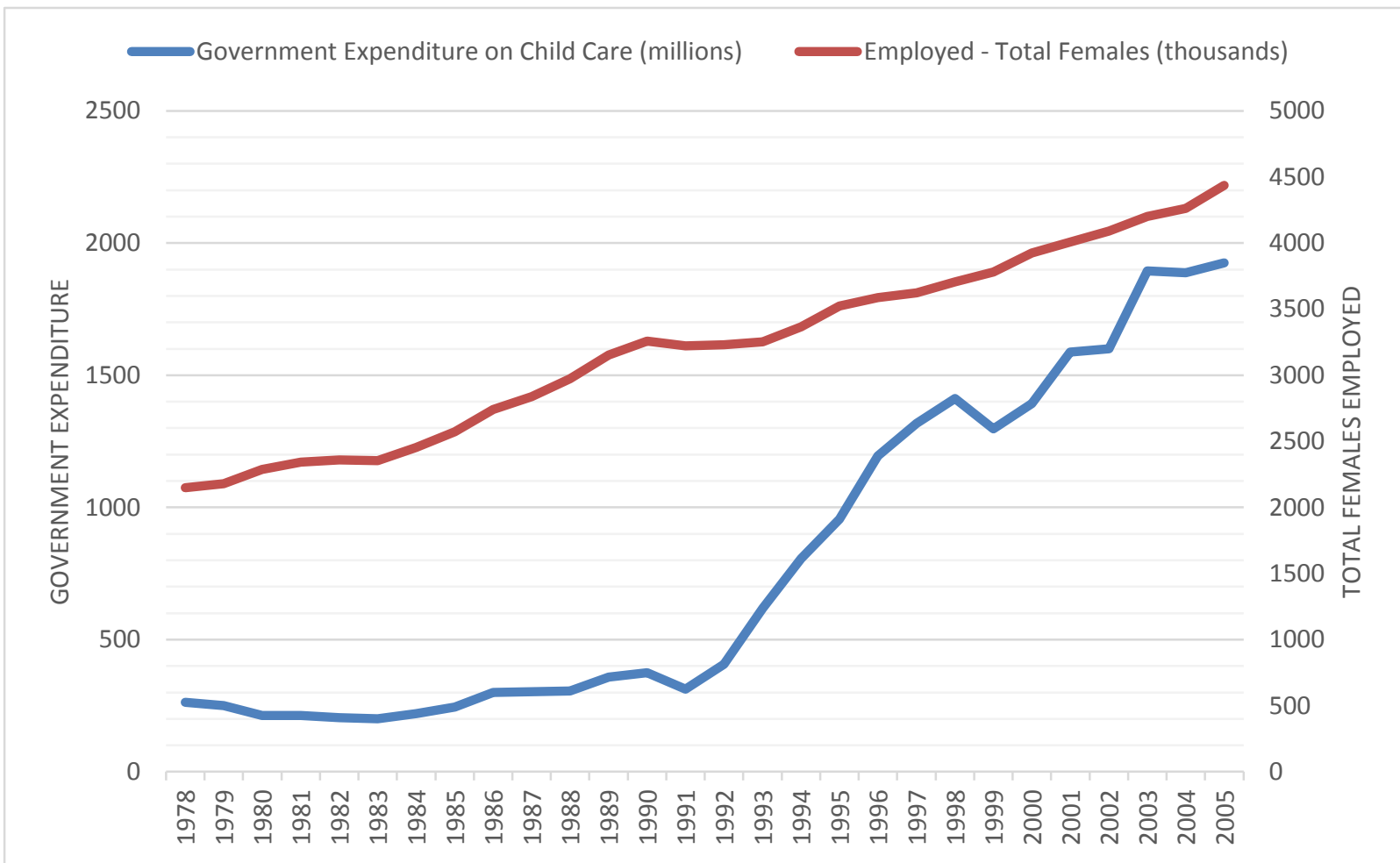

Source: ABS, Productivity Commission, cited in Buckingham, 2008 (See Table 2 in Appendix)

One of the most compelling counter points is what is known as the crowding out effect. According to Jennifer Buckingham (2008 p. 4), instead of subsidies causing parents with children not currently in child care to enrol, the trends suggest that parents who already have their children enrolled in an informal type of child care are more inclined to swap over to formal child care (See Table 1 in Appendix); thereby, not raising the WLFP rates. Buckingham (2008, p.2) also pointed out that between 1974 and 2007 WLFP increased 50\% (for women aged 2534 \& 35-44 years), whilst within that same period government spending on child care saw an 
increase of $4000 \%$. The fact that this government spending predominately occurred in the 1990 s and yet the increase in WLFP was occurring prior to this, in the 1980s, goes a long way to suggest that there is not a strong relationship between the two factors.

\section{The Analysis}

The objective of our data analysis is to establish through quantitative evidence the degree of association between the two variables and determine the legitimacy of government subsidies as an incentive for working mothers or whether there are external factors confounding this relationship.

Figure 1 plots the Government expenditure on childcare against the total employed females in Australia from 1978-2005. Clearly, the relationship between GECCS and WLFP is positive as would be expected.

We must determine whether or not the strength of the positive correlation is enough to rule in favour of our hypothesis; more specifically, if the independent variable is able to explain the variation in WLFP we can conclude in favour of our hypothesis. To assist in this process we intend to isolate periods of significant changes in our independent variable and gauge the function of the correlation during those periods.

During the early 1990's there was an expansion of the child care system formalised by the Australian government which included the development of 50,000 new facilities to be completed by 1996. The plan also included the initiative to extend fee relief to commercial childcare centres, which had previously only been available to not-for-profit centres (Childcare in Australia 2013). The endeavours of the Australian government to expand child care subsidies during this period is observable in the graph above.

By isolating a thirteen year period before and after the expansion we will be able to gauge whether the explanatory variable holds any bearing on rate of the increase in WLFP. 
Table 1: Regression output for 1978-1991\& 1992-2005

\begin{tabular}{|l|l|l|}
\hline Period & $1978-1991$ & $1992-2005$ \\
\hline R Square & 0.753253 & 0.929768 \\
\hline Observations & 14 & 14 \\
\hline Significance F & $5.74 \mathrm{E}-05$ & $2.79 \mathrm{E}-08$ \\
\hline Coefficient & 5.939866 & 0.776536 \\
\hline Coefficient p-value & $5.74 \mathrm{E}-05$ & $2.79 \mathrm{E}-08$ \\
\hline
\end{tabular}

To test our hypothesis an Analysis of Variance (ANOVA) was conducted. For the analysis we will focus on the p-value to determine whether or not the relationship is considered statistically significant ( $\mathrm{p}<0.05$ ), the regression coefficient and also the $R^{2}$ value to gauge the explanatory capacity of the independent variable.

The regression analysis in Table 1 reveals that only $75.33 \%$ of the variance in WLFP can be explained by government subsidies for the period before the expansion of the childcare system (1978-1991). However, in this period the ANOVA is considered significant indicating that Rsquare does significantly depart from zero, $R^{2}=0.75, F(1,12) p=0.000057$. In other words, government subsidies account for more of the variance in WLFP than we would expect by chance.

An ANOVA run after the expansion (1992-2005) also revealed statistically significant results, $R^{2}=0.93, F(1,12) p=0.000000028$. However the results of the output indicate that following the government expansion of the childcare system the relationship has developed more significance with the p-value falling well below 0.05 and also below the p-value of the previous period. Furthermore the ANOVA reveals that the explanatory capacity of government subsidies after the expansion has increased to $93 \%$, a result that supports our hypothesis. 
The regression coefficients represent the mean change in the response variable for one unit of change in the predictor variable. From our output we can observe that before the expansion a \$1 million increase in GECCS would increase WLFP by 5940 workers. Interestingly, for the period after the expansion a \$1million increase in GECCS would only increase WLFP by 777 workers.

Whilst we conjectured that an injection of funding would increase the regression coefficient post expansion, the reality is that WLFP had been steadily rising well before the government's expansion efforts. Although the predictive power of the GECCS has increased over this period, it should not be seen as the driving force behind the increase in WLFP.

\section{Other Factors influencing female labour force participation}

Whilst the influence of Government subsidies on childcare may hold some bearing on the female participation rate, there are certainly external factors influencing our dependant variable which are also changing over time.

\subsection{Taxation}

While some factors affecting WLFP (labour market conditions, cultural attitudes etc.) cannot rapidly be changed by policy reform, other factors such as taxation can. In most OECD countries second earners in married couples (typically women) are taxed more heavily than single individuals, discouraging participation; 'a family has one child under 5 and each parent earns $\$ 45,000$ annually, their gains are zero. A family that can earn the same joint income with only one parent in work gains a $\$ 2,195$ tax cut (Apps 2004, p.12).'

In Australia, the tax system act introduced by the Liberal government in 2000 is considered a catalyst for increases in the female labour supply. The act included lowering marginal income tax rates and increasing the thresholds at which the rates start to apply; the effects were significant (Australian Government: Budget 2007-08).

In particular, the increases announced in the 2006-07 and 2007-08 Budgets in the 30 per cent tax threshold from $\$ 21,601$ to $\$ 30,001$ and the substantial increases in the Low Income Tax 
Offset have increased incentives for workforce participation, particularly for secondary income earners (Australian Government: Budget 2007-08). The overall effect is regarded as having enhanced international competitiveness of Australia's personal income tax system; maintaining this competitiveness is essential for sustaining workforce participation.

\subsection{Education}

Figure 2: Contribution of explanatory variables to female participation

Figure 9. Contributions of explanatory variables to fermale participation, 1999

Per cent deviation of female participation from OECD mean'. :

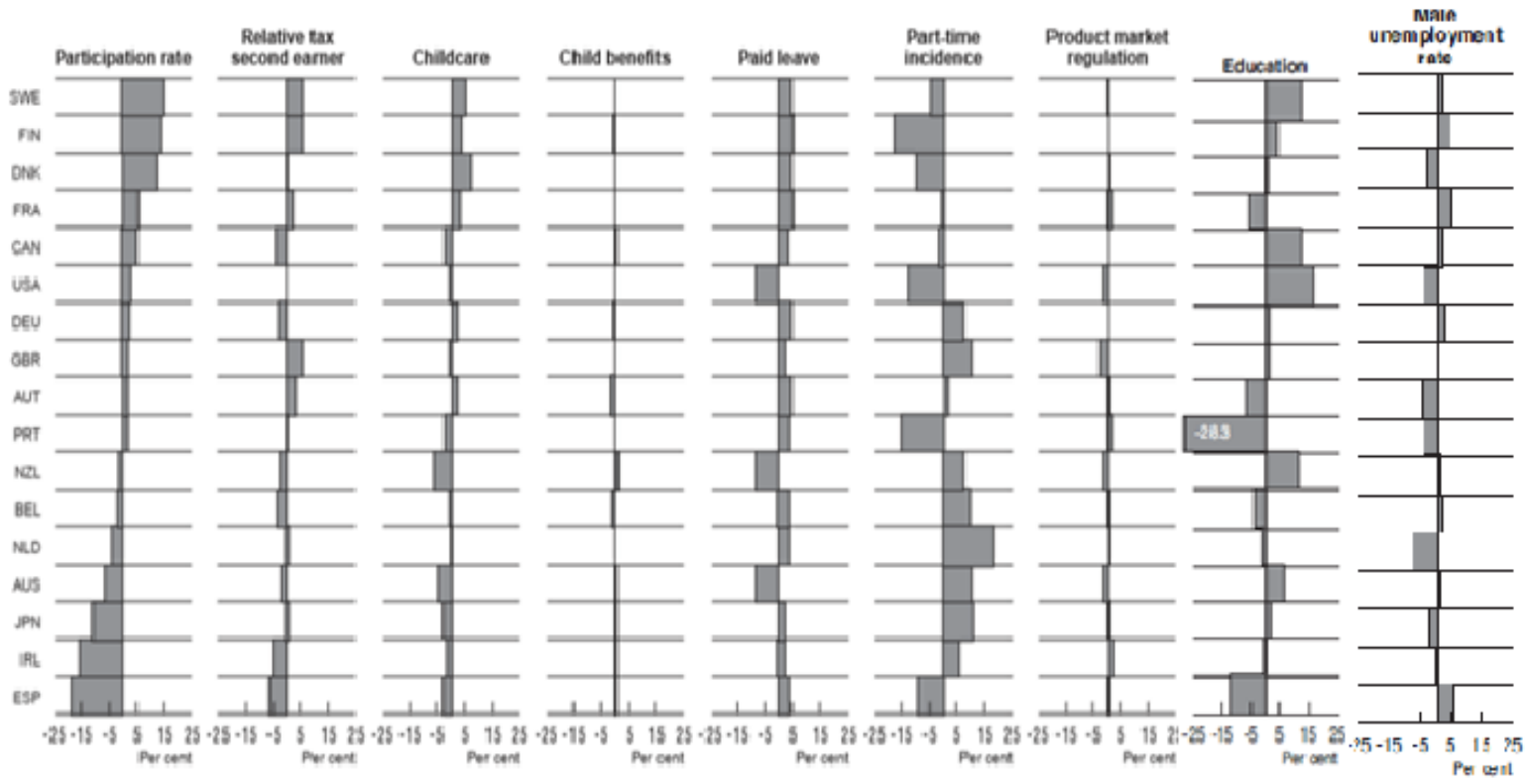

Figure 2 decomposes the percentage deviation of each country's female participation rate from the OECD average in 1999. The Graph also exhibits the various explanatory variables affecting female labour force participation and their deviation from the OECD average (OECD estimates, cited in Jaumotte 2003).

By examining the OECD averages of explanatory variables affecting female labour force participation it is clear that education bears a significant influence in Australia (See Figure 9). 
According to Kennedy, Stoney and Vance (2009, p. 10), in a study on the effect of education levels on labour force participation of men and women between 1981 to 2006, their study concluded that participation for all educational attainment groups for women has steadily risen over time. Following this, Kennedy and Hedly (cited in Australian Government 2005) found a notable correlation between education level and employment which also exhibited a steady increase for WLFP rates regardless of education level.

Figure 2 suggests that while education is a relatively strong factor for WLFP rates in Australia, childcare and taxes are not, therefore it is not clear if we can strongly conclude that the subsidy has had an effect on childcare decisions.

\section{Conclusion}

WLFP has a significant positive relationship with the use of child care subsidies within Australia. However, the average increase in WLFP has diminished with additional subsidies, notably, as we compare the early period 1978-1991 and 1992-2005. In addition, because we do not control for changes in the education of women over this period, it is not clear if increase in WLFP can be directly attributable to the subsidy.

\section{Limitations}

This study focused only the data of WLFP after the 1978 and compared this data with GECCS while assuming the changes in WLFP are due to changes in GECCS. Nevertheless, with such a broad concept there are numerous other factors that could also act as influences. Taxation changes coming out of the government, migration, the growth of the labour force and the impact of education levels of women and any other factors that could on their own, or in combination with others impact WLFP.

We were unable to obtain female employment data before 1978 relating to before the introduction of the child care subsidy and therefore we were unable to run a comparison equating the before data to make the findings more encompassing. 
This study also ignores the time value expect of the GECCS and the obvious rise in cost of childcare over the period of the study. The government expenditure on child care curve in Figure 1 would have appeared gentler had we made such adjustments in our analysis.

\section{References}

Apps, P 2004, 'The high taxation of working families', Australian Review of Public Affairs, vol. 5, no. 1, pp, 1-24.

Apps, P 2006, The New Discrimination and Childcare, Centre for Economic Policy Research, RSSS, ANU, viewed 19 March 2014, <https://digitalcollections.anu.edu.au/handle/1885/45261>.

Australian Bureau of Statistics 2007, Labour force participation - an international comparison, Australian Bureau of Statistics, viewed 28 March 2014, <http://www.ausstats.abs.gov.au/Ausstats/subscriber.nsf/0/A52A0BBD714A0982CA25 732F001C9C8C/\$File/41020_Labour\%20force\%20participation\%20\%20an\%20international\%20comparison_2007.pdf >.

Brennan, D 2007, 'Babies, Budgets, and Birthrates: Work/Family Policy in Australia 19962006', Social Politics: International Studies In Gender, State \& Society, vol. 14, no. 1, pp. 31-57.

Breunig, R V, Gong, X \& Trott, D 2012, The new national quality framework: quantifying some of the effects on labour supply, child care demand and household finances, Robert Breunig, viewed 23 April 2014, <http://scholar.google.com.au/scholar?hl=en\&q=The+new+Nati+o+n+a+l+Q+u+a+l+it 
$\mathrm{y}+$ Framework\%3A+Quanti+fying+some+of +the+effects+on+labour+supply $\% 2 \mathrm{C}+$ chil $\mathrm{d}+$ care+demand+and+household+finances\&btnG $=\&$ as_sdt=1\%2C5\&as_sdtp=>.

Buckingham, J, 23 July 2008, 'Child Care and Labour Supply,' The Centre for Independent Studies, no. 97, viewed 22 May 2014, <http://www.cis.org.au/images/stories/issueanalysis/ia97.pdf >.

Connelly, R 1992, 'The Effect of Child Care Costs on Married Women's Labor Force Participation', The Review of Economics and Statistics, vol. 74, no. 1, pp. 83-90.

Department of Education, Employment and Workplace Relations 2013, Childcare in Australia, viewed 25 April 2014, <http://www.deewr.gov.au>.

Department of Education, Employment and Workplace Relations 2010, State of Child Care in Australia, viewed 17 March 2014, <http://www.mychild.gov.au/documents/docs/StateofChildCareinAustralia-web.pdf>.

Evans, MD \& Kelley, J 2008, 'Trends in women's labor force participation in Australia: 1984-2002', Social Science Research, vol. 37, no. 1 pp. 287-310.

Hegewisch, A \& Gornick, JC 2011, 'The impact of work-family policies on women's employment: a review of research from OECD countries', Community, Work \& Family, vol. 14, no. 2, pp. 119-138.

Irvine, S \& Farrell, A 2013, 'The rise of government in early childhood education and care following the Child Care Act 1972: The lasting legacy of the 1990s in setting the reform agenda for ECEC in Australia', Australasian Journal Of Early Childhood, vol. 38, no. 4, pp. 99-106.

Jaumotte, F 2003, 'Labour force participation of women: Empirical evidence on the role of policy and other determinants in OECD countries', OECD Economic Studies, No. 37 , pp. 51-108. 
Kimmel, J 1998, 'Child Care Costs as a Barrier to employment for Simple and Married Mothers', Review of Economics \& Statistics, vol. 80, no. 2, pp. 287-299.

Rammohan, A \& Whelan, S 2005, 'Child care and female employment decisions', Australian Journal of Labour Economics, vol. 8, no. 2, pp. 203-225.

Rammohan, A \& Whelan, S 2007, 'The impact of childcare costs on the full-time /part-time employment decisions of Australian mothers', Australian Economic Papers, vol.46, pp.152-169.

Shlay, A, Weinraub, M, Harmon, M, \& Tran, H 2003, 'Barriers to subsidies: Reasons why low-income families do not use child care subsidies', Conference Papers -- American Sociological Association, pp. 1-40, SocINDEX with Full Text, viewed 5 May 2014, < http://eds.a.ebscohost.com/eds/pdfviewer/pdfviewer?sid=eaa0aeac-e181-4888-a78ab1f0df46ed4a\%40sessionmgr4002\&vid=3\&hid=4113 >.

Teal, F 1992, 'The Use and Cost of Child Care in Australia', Australian Economic Review, vol. 25 , no. 1 , pp. 3-14. 


\section{Appendices}

Appendix 1

\begin{tabular}{lrrrr} 
& Nov. 1984 & Jun. 1993 & Jun. 2005 & Jun. 2011 \\
& Percentage & & & \\
Any child care & $\mathbf{7 1 . 3}$ & $\mathbf{7 6}$ & $\mathbf{8 0 . 2}$ & $\mathbf{8 0 . 3}$ \\
Formal care only & 12.3 & 16.2 & 22.9 & 32.6 \\
Informal care only & 51.8 & 46.3 & 36.3 & 26.7 \\
Formal and informal care & 7.1 & 13.5 & 21 & 21 \\
\hline
\end{tabular}

\section{Female labour force participation} 45.6

51.4

57.1 58.9

Source: ABS

\section{Appendix 2}

\begin{tabular}{|c|cc|} 
YEAR & $\begin{array}{c}\text { Government } \\
\text { Expenditure } \\
\text { on Child } \\
\text { Care } \\
\text { (millions) }\end{array}$ & $\begin{array}{c}\text { Employed - } \\
\text { Total } \\
\text { Females } \\
\text { (thousands) }\end{array}$ \\
\hline $\mathbf{1 9 7 5}$ & 50 \\
$\mathbf{1 9 7 6}$ & 225 & \\
$\mathbf{1 9 7 7}$ & 275 & 2149 \\
$\mathbf{1 9 7 8}$ & 263 & 2178 \\
$\mathbf{1 9 7 9}$ & 250 & 2288 \\
$\mathbf{1 9 8 0}$ & 213 & 2343 \\
$\mathbf{1 9 8 1}$ & 213 &
\end{tabular}




\begin{tabular}{|c|c|c|}
\hline $\mathbf{1 9 8 2}$ & 205 & 2359 \\
$\mathbf{1 9 8 3}$ & 200 & 2353 \\
$\mathbf{1 9 8 4}$ & 220 & 2452 \\
$\mathbf{1 9 8 5}$ & 245 & 2573 \\
$\mathbf{1 9 8 6}$ & 300 & 2740 \\
$\mathbf{1 9 8 7}$ & 303 & 2839 \\
$\mathbf{1 9 8 8}$ & 305 & 2975 \\
$\mathbf{1 9 8 9}$ & 358 & 3152 \\
$\mathbf{1 9 9 0}$ & 375 & 3258 \\
$\mathbf{1 9 9 1}$ & 313 & 3223 \\
$\mathbf{1 9 9 2}$ & 406 & 3232 \\
$\mathbf{1 9 9 3}$ & 619 & 3252 \\
$\mathbf{1 9 9 4}$ & 806 & 3367 \\
$\mathbf{1 9 9 5}$ & 956 & 3523 \\
$\mathbf{1 9 9 6}$ & 1195 & 3587 \\
$\mathbf{1 9 9 7}$ & 1318 & 3623 \\
$\mathbf{1 9 9 8}$ & 1413 & 3705 \\
$\mathbf{1 9 9 9}$ & 1298 & 3780 \\
$\mathbf{2 0 0 0}$ & 1393 & 3926 \\
$\mathbf{2 0 0 1}$ & 1588 & 4008 \\
$\mathbf{2 0 0 2}$ & 1600 & 4090 \\
$\mathbf{2 0 0 3}$ & 1895 & 4202 \\
$\mathbf{2 0 0 4}$ & 1888 & 4261 \\
$\mathbf{2 0 0 5}$ & 1925 & 4437 \\
Source: ABS, Productivity Commission & \\
\hline
\end{tabular}

